\title{
Commentary \\ Setting ambitious goals for agriculture to meet environmental targets
}

\author{
Jan Willem Erisman ${ }^{1, *}$ \\ ${ }^{1}$ Institute of Environmental Sciences, Leiden University, the Netherlands \\ *Correspondence: j.w.erisman@cml.leidenuniv.nl \\ https://doi.org/10.1016/j.oneear.2020.12.007
}

Food production in the Netherlands is an economic success but has led to many environmental issues, including nitrogen pollution. Recently, the policy to allow economic growth while reducing nitrogen losses was disapproved by the highest court in the Netherlands, casting the country into a nitrogen crisis. More integrated policies are necessary for global future sustainable food production.

The invention of the chemical fixation of atmospheric nitrogen lifted limitations on the use of fertilizer for food production, staved off global hunger, and significantly boosted population. But this human innovation success story has come with a tremendous environmental cost. ${ }^{1}$ In addition to having fundamentally altered physical, societal, industrial, and economic landscapes, the world now has an excess of reactive nitrogen ( $\mathrm{Nr}$ ), which is polluting water courses, leading to biodiversity loss, exceeding safe thresholds for drinking-water quality (as a result of nitrates), and reducing air quality via smog, particulate matter, and ground-level ozone. Climate change and stratospheric ozone depletion-not to mention the proliferation of coastal ecosystem "dead zones," which, as a result of eutrophication, have increased from just nine in the 1960s to over 500 today $^{2}$-are also consequences of the human-modified Nr cycle (Figure 1). Each of these environmental effects can be magnified by a "nitrogen cascade" whereby a single $\mathrm{Nr}$ atom can trigger a sequence of negative environmental impacts through time and space. ${ }^{3}$

In 2009, Rockström et al. ${ }^{4}$ introduced the concept of planetary boundaries: nine essential Earth subsystems each with their own critical biophysical thresholds, which if breached could compromise the safe operating space of the planet. Nitrogen is one such subsystem, and because of the extent to which humans have removed $\mathrm{Nr}$ from the atmosphere for our own use, it is one for which the critical threshold has been far exceeded. ${ }^{5,6}$

It is now clear that the nitrogen problem is one of the most pressing environmental issues that we face. But in spite of the enormity of our influence on the $\mathrm{Nr}$ cycle and consequent implications for the environment and human well-being, surprisingly little attention is paid to the issue. Although biodiversity loss and climate change have spawned huge budgets for creating national and interdisciplinary programs, global organizations, and political and media attention, the $\mathrm{Nr}$ challenge remains much less apparent in our thinking and actions. ${ }^{7}$ Is this because we are educated with the important role that $\mathrm{Nr}$ plays with regard to food security? Or perhaps we are unaware becausecompared with climate change or biodiversity loss $-\mathrm{Nr}$ overuse and emissions are seldom discussed by the scientific community.

There is, however, one country in the world where nitrogen is frontpage news and high on the political agenda: the Netherlands is experiencing a nitrogen crisis.

Tiny country, big agriculture

"This tiny country feeds the world" read the headline of the September 2017 issue of National Geographic. Despite a land area that is 270 times smaller than the US, the Netherlands is ranked second largest in the world (after the US) for agricultural exports. For every one of the country's 17 million inhabitants, there exist eight chickens, one pig, and a quarter of a cow all being housed and fed and $14 \mathrm{~kg}$ of fertilizer used. Yields and production per hectare are the highest in the world, especially for onions, potatoes, seeds, and cheese. Dutch agriculture is highly productive, innovative, diverse, and export oriented. ${ }^{8}$ Livestock and crop sectors deliver almost equal shares of output value with a significant contribution from both open-field and greenhouse horticulture. As a result, the Netherlands' agricultural export industry is worth almost $€ 100$ billion per year, and agri-food products account for roughly $20 \%$ of the country's total export value.

Agriculture is clearly economically important in the Netherlands, but it is also environmentally problematic. the Netherlands has been the European nitrogen hotspot since the 1980s, and agriculture is the dominant source in that it contributes $46 \%$ to nitrogen deposition. ${ }^{9}$ Nitrogen losses from manure and mineral fertilizer are the result of overapplication following the introduction of agricultural policies induced by the Marshall Plan after World War II, mechanization, and intensification. Although the implications of nitrogen pollution have long been recognized and policies to limit nutrient losses have been relatively successful-ammonia and nitrogen oxide emissions have declined by $60 \%$ since 1990 -recent events have highlighted the complexity of the nitrogen challenge and the need for more integrated approaches. Despite these reductions, harmful nitrogen deposition to $75 \%$ of the Netherlands' sensitive Natura 2000 areas-habitats for charismatic species in need of protection-is two times higher than the critical load.

Nitrogen policy judged insufficient In 2015, the Dutch government introduced the Programmatic Approach on $\mathrm{Ni}$ trogen (PAS). The PAS was effectively a nitrogen-licensing system that enabled businesses to emit nitrogen so long as these emissions were compensated for 


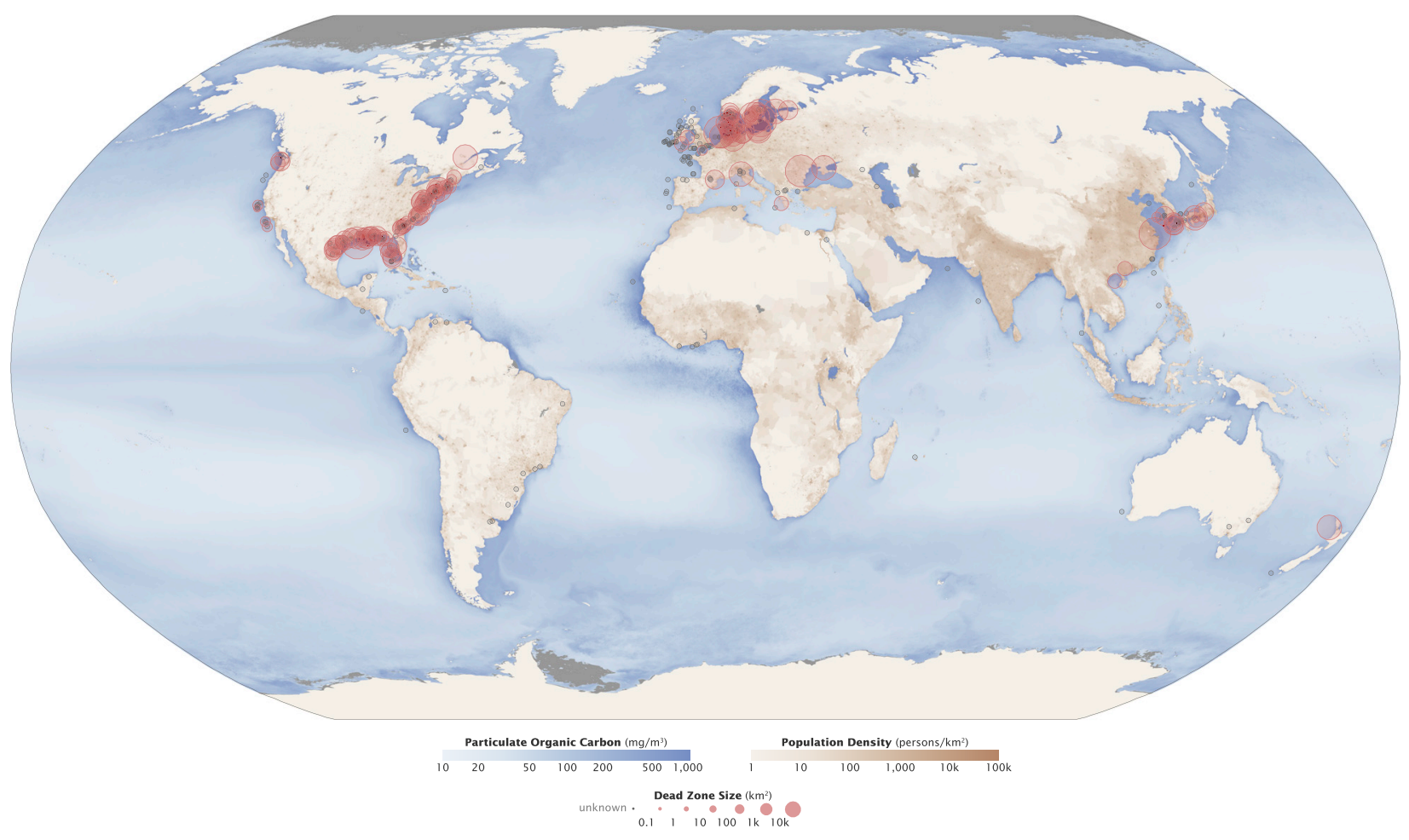

Figure 1. The size and number of the world's dead zones, along with population density and particulate organic carbon

Map by Robert Simmon and Jesse Allen and based on data from Robert Diaz at the Virginia Institute of Marine Science (dead zones), the GSFC Ocean Color team (particulate organic carbon), and the Socioeconomic Data and Applications Center (population density): https://earthobservatory.nasa.gov/images/44677/ aquatic-dead-zones.

with technical (such as air scrubbers) and natural (such as extra mowing or lifting of the groundwater table) restoration measures that might deliver emission reductions in the future. This was seen as a smart compromise between emission reduction and economic growth.

However, anticipated emission reductions did not guarantee the required deposition reductions today, and in 2018, the European Court of Justice decided that the PAS was not sufficient to protect Natura 2000 areas from nitrogen pollution, a ruling subsequently supported by the State Council-the highest judge in the Netherlands. The ruling required a significant reduction in nitrogen to maintain the quality of Natura 2000 areas. It is not possible to appeal this judgement. The nitrogen licensing scheme was frozen, and as a consequence over 18,000 projects were blocked, including the building of new roads, housing, airports, windmill parks and industrial facilities, and new or expanding agricultural farms. Thousands of farmers lost their nitrogen rights. The economic loss was estimated to be over
$€ 14$ billion and will grow until a policy that can restart permitting is in place.

The only short-term option introduced by the government in response to the ruling was the reduction of the speed limit from 130 to $100 \mathrm{~km} / \mathrm{h}$ on highways during the daytime, which reduced nitrogen enough to enable the building of 75,000 houses. The government is currently proposing a new nitrogen law that should result in the protection of $74 \%$ of the $\mathrm{Na}$ tura 2000 areas by reducing the nitrogen deposition to below the critical loads in 2035. This goes along with a large budget for nature restoration. The government's total investment is $€ 5$ billion over 10 years mainly for agricultural and nature-recovery measures. Although the necessary reductions of $50 \%$ of the nitrogen oxide emissions are made possible by climate mitigation efforts (such as increased energy efficiency, the electrification of transport systems, and sustainable energy transitions), it is much harder to abate agricultural emissions, which account for the lion's share (46\%) of the problem, and so this will require a much broader approach to sustainable agriculture. The
Netherlands' nitrogen crisis highlights that the nitrogen challenge is an economic challenge and one to which farmers are most vulnerable.

\section{International challenge}

Dutch farmers are assembled in large cooperatives that operate on a world market where prices are constant and do not increase. On the other hand, production costs in the Netherlands are increasing as a result of environmental legislation, labor costs, and increasing input and land prices.

In order to face the nitrogen challenges and also reduce climate impacts, agriculture will require a gradual transition with difficult decisions, particularly in a global food market where the Netherlands cannot operate in isolation. But make no mistake: this challenge is not unique to the Netherlands; the nitrogen crisis has many implications for other nations. All nations with excess nitrogen, such as those shown in Europe in Figure 2, face similar challenges, and because of the worldwide growth in food production, the areas with nitrogen excess will also 


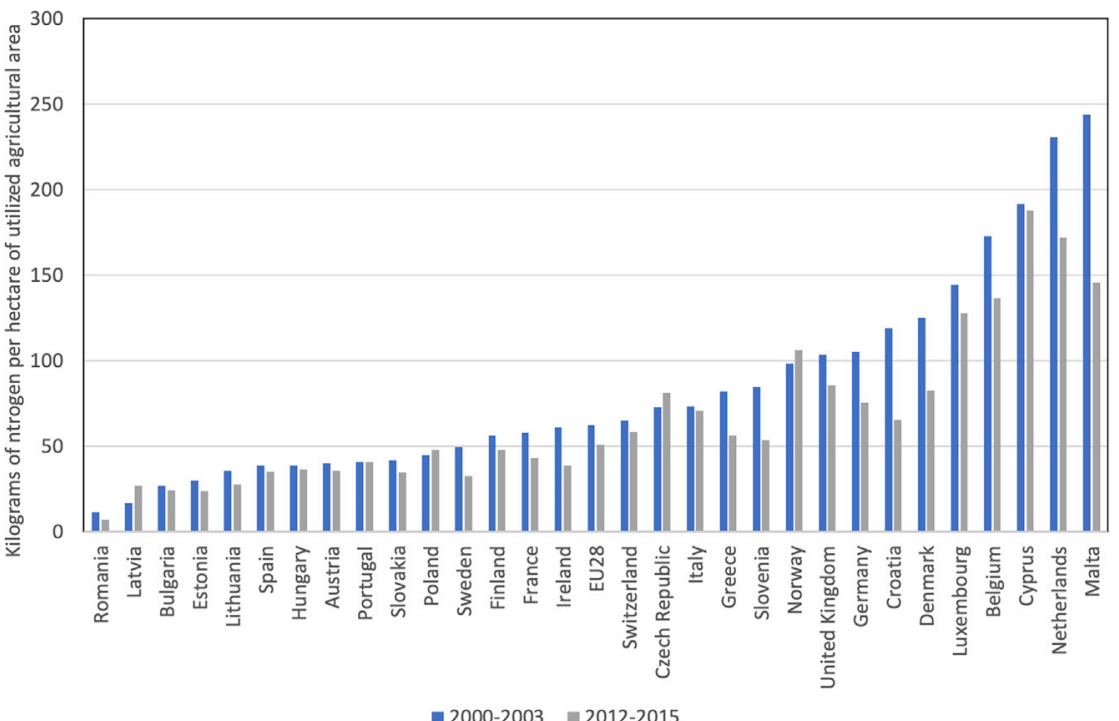

Figure 2. Average gross nitrogen balances

Balances in kg nutrient/ha for two time periods (2000-2003 and 2012-2015) at the level of the Member States. ${ }^{11}$

grow and need to move into more circular systems. The Dutch government has launched a vision for a more circular agricultural system as a solution, ${ }^{10}$ but a level playing field will be necessary for finding support, and policies would need to be introduced at the European level at the very least.

\section{Setting ambitious goals for the commons}

Although many players in the global food chain have a responsibility to make agriculture more sustainable, there is a special task for governments. In my view, the government in the Netherlands, as well as in other nations, should paint an inspiring picture of the future for sustainable agriculture and food chains. The government can make its vision of circular agriculture more concrete by introducing principles such as soil health as the basis for sustainable agriculture and spatial planning as a tool to produce food with less impact on nature, biodiversity, and the climate: our shared commons.

On the basis of that vision, the government should set clear legal (environmental) targets within which farmers (and other entrepreneurs) are free to operate. In instances where targets are not met, the government should then intervene. These targets should be concrete, science-based goals based on the UN Sustainable Development Goals and in measurement. This provides insight into how performance contributes to the realization of commons that provide a safe operating space for society. In instances where performance-or success - can be measured unambiguously, it is possible to reward farmers, for example, through interest rebates on loans, a higher price through customers, or lower taxes. This stacking of rewards provides additional incentives to farmers to score well on KPIs. We need a set of integral KPIs that steer the farmer's performance integrally in the right direction while also reducing nitrogen losses. The Netherlands has proposed this idea in their National Strategic Plan under the Common Agricultural Policy in order to base farmer support on actual environmental performance. The market can also use this system to reward certain performance and distinguish itself from other market parties. An example of a $\mathrm{KPI}$ system is the Biodiversity Monitor developed by the World Wildlife Fund, Rabobank, and FrieslandCampina for dairy farming. ${ }^{12,13}$

climate; the conservation of biodiversity; and the protection of nature, our landscapes, and animal welfare. The targets should, where necessary, be regionalized and timed. The targets should be accountable at the farm level or filed with regional authorities for enforcement. This makes it clear what the long-term task is. In principle, the Netherlands can do this for itself, but agreeing on the targets internationally, e.g., under the European Green Deal that was proposed in 2020, and translating them to other regions in Europe will strengthen Dutch policy. Instruments such as key performance indicators (KPIs), commonly used in the business domain, can be used to integrally steer indicators toward targets.

Such a system would offer opportunities to develop agricultural businesses integrally toward sustainable agriculture with social support and the capacity to monitor progress. It is, in my opinion, less important to prescribe what type of agriculture is adopted (e.g., nature based, circular, organic, or precision) than to set the right goals on the basis of the need to preserve our shared commons and to reward farmers and agricultural entrepreneurs on the basis of their achievements.

Target values provide direction and guidance for moving toward the ecological optimum and striving for unambiguity
Global sustainable food production

The nitrogen challenge in the Netherlands will certainly be followed in other areas in the world. Policies to stimulate food production without respect for the need to preserve our shared commons and the vital services they provide will contribute to and potentially even accelerate the exceedance of planetary boundaries, compromising a sustainable future for all. Current food policies encourage farmers to produce as much food as possible against the lowest costs in a global food market with low prices. A $\mathrm{KPI}$ system can stimulate farmers to produce food sustainably provided that clear environmental targets are set. Governments can balance farmers in environmental sensitive areas by using the KPIs to reward the preservation and protection of ecosystems and the services they provide, such as carbon sequestration, biodiversity, and landscape resilience. Without such measures, the nitrogen crisis will continue and worsen.

\section{REFERENCES}

1. Erisman, J.W Galloway, J.N., Sutton, M.S., Klimont, Z., and Winiwater, W. (2008). How a century of ammonia synthesis changed the world. Nat. Geosci. 1, 636-639. 
2. Diaz, R.J., and Rosenberg, R. (2008). Spreading dead zones and consequences for marine ecosystems. Science 321, 926-929.

3. Galloway, J.N., Aber, J.D., Erisman, J.W., Seitzinger, S.P., Howarth, R.W., Cowling, E.B., and Cosby, B.J. (2003). The nitrogen cascade. Bioscience 53, 341-356.

4. Rockström, J., Steffen, W., Noone, K., Persson, A., Chapin, F.S., 3rd, Lambin, E.F., Lenton, T.M., Scheffer, M., Folke, C. Schellnhuber, H.J., et al. (2009). A safe operating space for humanity. Nature 461, 472-475.

5. De Vries, W., Kros, H., Kroeze, C., and Seitzinger, S.P. (2013). Assessing planetary and regional nitrogen boundaries related to food security and adverse environmental impacts. Curr. Opin. Environ. Sustain. 5 392-402.

6. Steffen, W., Richardson, K., Rockström, J., Cornell, S.E., Fetzer, I., Bennett, E.M., Biggs, R., Carpenter, S.R., de Vries, W., de Wit, C.A., et al. (2015). Planetary boundaries:
Guiding human development on a changing planet. Science 347, 1259855

7. United Nations Environment Programme (2019). Frontiers 2018/19: emerging issues of environmental concern. https://www.unenvironment org/resources/frontiers-201819-emergingissues-environmental-concern.

8. Organisation for Economic Cooperation and Development (2015). Innovation, agricultura productivity and sustainability in the Netherlands. OECD Food and Agricultural Reviews (OECD Publishing). https://doi.org/ 10.1787/9789264238473-.

9. Environmental Data Compendium (2019) Nitrogen deposition, 1990-2018. Indicator 0189, version 18, November 25, 2019 (Statistics Netherlands, PBL Netherlands Environmental Assessment Agency, RIVM National Institute for Public Health and the Environment, and Wageningen University and Research). https://www.clo.nl/en/indicators/ en0189-nitrogen-deposition.
10. Ministry of Agriculture, Nature, and Food Quality (2018). Agriculture, nature and food: valuable and connected. https://www.government.nl/ ministries/ministry-of-agriculture-nature-andfood-quality/vision-anf.

11. European Environment Agency (2018). Gross nitrogen balance in Europe by country. https://www.eea.europa.eu/data-and-maps/ daviz/gross-nitrogen-balance-by-country1\#tab-chart_3.

12. Erisman, J.W., Van Eekeren, N., Koopmans, C., De Wit, J., Cuijpers, W., Oerlemans, N. and Koks, B. (2016). Agriculture and biodiversity: a better balance benefits both. AIMS Ag. Food 1, 157-174.

13. van Laarhoven, G., Nijboer, J., Oerlemans, N., Piechocki, R., and Pluimers, J. (2018). Biodiversity monitor for the dairy sector, (Rabobank, FrieslandCampina, and WWF). http://biodiversiteitsmonitormelkveehouderij. $\mathrm{nl} /$ docs/Biodiversiteitsmonitor engels.pdf. 